\title{
As práticas pedagógicas e o material didático do Programa Ler e Escrever no $1^{\circ}$ ano do ensino fundamental
}

Tatiana Cristina Santos

Elvira Cristina Martins Tassoni

http://dx.doi.org/10.1590/S2176-6681/32612879

\section{Resumo}

Apresenta resultados de pesquisa que objetivou investigar como a proposta do material didático do Programa Ler e Escrever (PLE) foi vivenciada pelos alunos e pela professora de uma sala de $1^{\circ}$ ano do ensino fundamental (EF), em uma escola estadual de Campinas, no Estado de São Paulo. O PLE é um programa estadual que compreende um conjunto de ações visando à melhoria da qualidade da alfabetização nos anos iniciais do EF. Uma de suas principais ações consiste na elaboração e distribuição de material didático. Os procedimentos de coleta de dados incluíram: observações em sala de aula, entrevista com a professora e entrevistas com os alunos. Alguns recursos auxiliares, como microfone, câmera fotográfica e uma boneca-personagem, foram utilizados durante as 
entrevistas com as crianças. Os resultados apontaram o grande desejo dos alunos em saber ler e escrever, pois isso lhes concede maior autonomia e acesso a informações importantes haja vista que a leitura e a escrita estão diretamente relacionadas ao conhecimento. Os alunos demonstraram anseio por compreender o funcionamento e a finalidade da escrita. $\mathrm{O}$ apoio do material didático pode contribuir, satisfatoriamente, para a aquisição da linguagem escrita, mas a mediação e o uso que se faz deste são fundamentais. Os gêneros explorados no material didático, tanto para a leitura como para a escrita, bem como os temas e o volume de material escrito disponibilizado, devem ser objeto de reflexão.

Palavras-chave: educação básica; ensino; aprendizagem; material didático.

\section{Abstract \\ Pedagogical practices and didactic material of the "Read and Write Program" in the first grade of elementary school}

This article presents results of research that aimed to investigate how the proposal of didactic material of the "Read and Write Program" (Programa Ler e Escrever - PLE) was experienced by first grade elementary students and by their teacher, in a public school of Campinas, in the State of São Paulo. The PLE is a program of the State of São Paulo, comprising a set of actions aimed at improving the quality of literacy in the early years of elementary school. One of its main actions is the development and distribution of educational materials. Data collection procedures included: classroom observations, interviews with the teacher and with the students. Some supplementary features, such as a microphone, a camera and a dollcharacter were used during the interviews with the children. The results showed the great desire of students in learning how to read and write, because it gives them more autonomy and access to important information, since reading and writing are directly related to knowledge. Students demonstrated desire for understanding the functioning and purpose of writing. The support of the educational material can satisfactorily contribute to the acquisition of written language, but the mediation and the use that is made of this material are essential. In relation to the teaching materials, the genres that are exploited both for reading and writing, as well as the topics and the volume of written material made available should be object of reflection.

Keywords: basic education; teaching; learning; didactic material. 


\section{Introdução}

Os primeiros anos do ensino fundamental (EF), especialmente nas últimas décadas, têm sido foco de propostas educacionais na esfera federal e nas esferas estaduais ou municipais, visando a melhorias na qualidade do ensino e no aprendizado da leitura e da escrita. No Estado de São Paulo (SP), especificamente, temos a proposta do Programa Ler e Escrever (PLE), que, de acordo com informações (São Paulo, 2010), se trata de um conjunto de ações direcionadas para os anos iniciais do EF e contempla a formação de professores, a elaboração e distribuição de materiais pedagógicos, entre outros subsídios, visando à melhoria da alfabetização na rede estadual.

No que se refere ao material didático, o PLE destinou para cada um dos anos iniciais do EF o livro do professor - Guia de Planejamento e Orientações Didáticas - e o livro do aluno - Coletânea de Atividades. Cabe salientar que os materiais elaborados e distribuídos pelo Programa Ler e Escrever, desde a sua institucionalização - que se deu pela Resolução SE no 22, de 29 de março de 2007 (São Paulo, 2007b) -, passaram a ser priorizados na prática pedagógica das escolas estaduais de $1^{\circ}$ a $5^{\circ}$ ano do Estado de São Paulo.

Seguindo essa perspectiva, o objetivo da pesquisa, aqui apresentada, foi investigar como a proposta contida no material didático do PLE foi vivenciada pelos alunos e pela professora de uma sala de $1^{\circ}$ ano do EF em uma escola estadual de Campinas (SP). Teve ainda três objetivos específicos: identificar como o uso da Coletânea de Atividades do $1^{\circ}$ ano do EF se concretiza em sala de aula; observar como os alunos desenvolvem as atividades contidas nas propostas do material; e analisar as impressões da professora e dos alunos sobre esse material.

A opção de investigar o $1^{\circ}$ ano se deu em virtude da recente ampliação do EF, com a promulgação da Lei $\mathrm{n}^{\circ}$ 11.274/06 (Brasil, 2006), que instituiu a matrícula obrigatória da criança aos seis anos de idade, implicando, portanto, a inclusão de um ano escolar no início da escolarização básica. $\mathrm{O} 1^{\circ}$ ano do EF foi instituído progressivamente nas escolas até o ano de 2010. O documento Ensino Fundamental de Nove Anos - Orientações Gerais (Brasil. MEC, 2004, p. 14) indica que essa medida visou não apenas ampliar o tempo de escolarização, como também proporcionar melhores condições de estudo, principalmente em relação à alfabetização da criança no primeiro ciclo desse nível de ensino.

\section{O Programa Ler e Escrever: justificativa e estrutura}

De acordo com a Resolução SE n 22, de 29 de março de 2007 (São Paulo, 2007b), o PLE é um programa de intervenção pedagógica na sala de aula e de intervenção na gestão da escola, envolvendo supervisor, diretor e coordenador pedagógico. A Resolução SE $\mathrm{n}^{\circ}$ 86, de 19 de dezembro de 2007 (São Paulo, 2007c), instituiu para o ano de 2008 o PLE nos anos iniciais 
do EF nas escolas estaduais da região metropolitana da Grande São Paulo, sob a regência da Coordenadoria de Ensino da Grande São Paulo (COGSP). O Comunicado da Secretaria da Educação do Estado de São Paulo (SEE) (São Paulo, 2007a), de 19 de dezembro de 2007, publicado no Diário Oficial do Estado (DOE) em 21 de dezembro de 2007, considerando as disposições dessa Resolução, tornou públicas as orientações para a implantação do PLE nas escolas da rede pública estadual no início do ano seguinte, em 2008. Cabe destacar que antes disso, em 2006, o Programa havia sido implantado no município de São Paulo.

Considerando os resultados alcançados com a implantação do Programa na região metropolitana de São Paulo, a partir do ano de 2009, conforme estabelecido pela Resolução SE n 96, de 23 de dezembro de 2008 (São Paulo, 2008), o PLE se estende para as escolas do litoral e interior paulista, sob a responsabilidade da Coordenadoria de Ensino do Interior (CEI). A implantação do Programa em todo o Estado de São Paulo obedeceu às normas e orientações definidas na Resolução SE nº 86/2007 (São Paulo, 2007b).

Salientamos que o Ler e Escrever surge também da urgência em solucionar as dificuldades apresentadas pelos alunos nos primeiros anos do EF em relação às competências de ler e escrever, expressas nos resultados do Saresp ${ }^{1}$ 2005. Dessa forma, em 2007, a Secretaria da Educação do Estado (SEE) desenvolveu ações com a finalidade de melhorar a qualidade do ensino instituindo metas elaboradas pelo governo estadual com previsão para efetivação até o ano de 2010. ${ }^{2}$ Destacamos duas dessas metas emergenciais: a plena alfabetização de alunos com oito anos de idade e a promoção da aprendizagem daqueles que não atingiram as expectativas previstas para os primeiros anos do EF. Como medida para atingir tais metas, consolida-se e estende-se o PLE para todo o Estado de São Paulo.

Em relação às ações de formação, segundo informações contidas no Comunicado da SEE, o Ler e Escrever, em 2007, envolveu as diretorias de ensino da capital paulista, nas quais se deu, em um primeiro momento, a formação de gestores e a formação pedagógica. A formação dos professores acontece nas próprias unidades escolares em momentos de reuniões pedagógicas denominadas Aulas de Trabalho Pedagógico Coletivo (ATPC), organizadas pelos professores coordenadores (PC), que são formados nas diversas diretorias de ensino.

Outras ações para o cumprimento das metas e dos objetivos do Programa são: recuperação da aprendizagem para o $4^{\circ}$ e $5^{\circ}$ ano; presença de um aluno pesquisador bolsista em cada sala de aula (estudante de Pedagogia ou de Letras, numa parceria entre SEE e universidade); distribuição de materiais complementares, tais como acervo literário e paradidático para a biblioteca de sala de aula, enciclopédias, globos, letras móveis, calculadoras, etc.; acompanhamento institucional sistemático às diretorias de ensino para apoiar o desenvolvimento do trabalho (São Paulo, 2010).

A respeito da composição do material didático para o trabalho pedagógico em sala de aula, como já apresentado, há, para cada ano escolar, um Guia de Planejamento e Orientações Didáticas destinado ao professor e

\footnotetext{
${ }^{1}$ O Sistema de Avaliação de Rendimento Escolar do Estado de São Paulo (Saresp) consiste em avaliação externa em larga escala, criada e operacionalizada pela Secretaria da Educação do Estado de São Paulo (SEE), desde 1996. Sua finalidade é produzir um diagnóstico da situação da escolaridade básica na rede pública de ensino paulista, visando orientar os gestores do ensino no monitoramento das políticas voltadas para a melhoria da qualidade educacional. O Saresp está aberto à participação das redes municipais e escolas particulares por meio de adesão. Disponível em: http://saresp.fde. sp.gov.br. Acesso em: abr. 2012.

2 Tais metas baseiam-se no estipulado também pelo Decreto $\mathrm{n}^{\circ}$ 6.094, de 24 de abril de 2007, que dispõe sobre a implementação do Plano de Metas Compromisso Todos pela Educação (Brasil, 2007).
} 
uma Coletânea de Atividades, destinada aos alunos. Há também o Livro de Textos do aluno para ser trabalhado do $1^{\circ}$ ao $5^{\circ}$ ano, além de ser indicado como material de leitura a ser realizada em casa, junto aos familiares.

$\mathrm{O} 1^{\circ}$ ano do EF foi contemplado com o material didático do Programa Ler e Escrever em 2011. No Guia de Planejamento e Orientações Didáticas (São Paulo, 2011a), encontramos instruções de como organizar a rotina, o tempo, o espaço e os materiais, com o intuito de potencializar as oportunidades de aprendizagem, além de proporcionar ambiente engajado com o universo desses alunos. A Coletânea de Atividades (São Paulo, 2011b) está dividida em três partes: Leitura e Escrita, Projeto Brincadeiras Tradicionais e Projeto Índios do Brasil - Conhecendo algumas Etnias. De forma geral, nas atividades estão previstas situações de comunicação oral, trabalho com textos, como cantigas, parlendas e textos informativos. A indicação presente nas estratégias de aprendizagem é a de que, desse modo, os alunos teriam condições de relacionar as características linguísticas, estruturais, semânticas e a função social de diferentes textos. É enfatizada a leitura e a escrita coletiva, a fim de oportunizar ao aluno a compreensão e assimilação de regularidades sobre a língua e também a realização de associações, a identificação de letras e palavras, assim como a ampliação da compreensão da escrita em diferentes situações.

A metodologia preconizada nas orientações das atividades segue a perspectiva da resolução de situações-problema. Indicamos, conforme a concepção do material pesquisado, que os passos da resolução de problemas compreendem a análise da situação, a identificação de aspectos mais relevantes, a reflexão e interpretação dos fatores implicados no contexto, a busca por recursos de solução, a aplicação dos conhecimentos, o levantamento de hipóteses ante a possibilidade de encontrar respostas, o ajuste de estratégias já utilizadas em outras situações e a ponderação de que são pertinentes para o problema apresentado. Por fim, a tomada de decisão em relação ao melhor encaminhamento para a situação a ser resolvida (São Paulo, 2011a).

\section{Percurso metodológico: os meandros da pesquisa de campo}

O desenvolvimento da pesquisa contou com os seguintes procedimentos metodológicos: observações em uma sala de aula do $1^{\circ}$ ano do EF em uma escola estadual de Campinas (SP), entrevistas com as crianças e com a professora responsável pela sala pesquisada.

As observações em sala de aula tinham por objetivo promover o contato com as crianças, a fim de ambientá-las para o momento da entrevista, assim como conhecer de que maneira as propostas envolvendo o material do Programa se concretizaram em sala de aula. As observações foram registradas em diário de campo, instrumento de registro que Pádua (2000) destaca ser um elemento importante para a orientação do estudo científico, pois permite a retrospectiva do trabalho realizado. O registro também contou com um roteiro prévio de observação, que destacou o desenvolvimento das 
propostas, no que diz respeito à forma de apresentação, às estratégias e às mediações utilizadas pela professora e ao tipo de exploração realizado por ela. Em relação aos alunos, centramo-nos no modo como se comportaram e realizaram a atividade, qual a compreensão sobre a proposta, quais as dúvidas e dificuldades.

Como aborda Cruz (2008), a escuta de crianças em pesquisas é algo contemporâneo. Mesmo assim, Rocha (1999) afirma que são mais comuns pesquisas realizadas "sobre crianças do que com crianças". Dar voz às crianças na pesquisa é um desafio e requer alguns cuidados. Optamos por realizar as entrevistas em duplas e trios, acreditando que, no diálogo em pequenos grupos, as crianças poderiam se expressar com mais qualidade. Outro cuidado foi a utilização de elementos que auxiliaram a mediação entre o pesquisador e as crianças: uma manta para forrar a mesa, um microfone infantil para organizar o momento da fala de cada criança, uma bonecapersonagem do tipo fantoche, que, de um lado, representava a Narizinho e, do lado avesso, a Emília - personagens do Sítio do Picapau Amarelo, obra de Monteiro Lobato -, e, ainda, uma câmera fotográfica para que registrassem as atividades que desejassem.

Iniciamos a entrevista apresentando para as crianças a Narizinho, dizendo que ela ia à escola e que lá havia um material didático parecido com o delas. Após essa contextualização, introduzia-se a Emília, dizendo que ela não ia à escola e não conhecia material didático algum, e que gostaria de conhecer o material que as crianças usavam. Nesse momento, perguntávamos se as crianças gostariam de contar como era o material do PLE. Esse procedimento segue o apresentado por Passeggi et al. (2012), em um estudo a respeito da compreensão das crianças sobre as escolas da infância. Cabe informar que, para essa atividade, também foi elaborado previamente um roteiro que norteou os procedimentos e aspectos a serem explorados durante as entrevistas. Foram entrevistadas dezesseis crianças, de acordo com a autorização prévia de seus responsáveis legais.

A escola escolhida é bem estruturada e organizada, tanto no aspecto físico quanto em relação à gestão escolar e ao trabalho pedagógico desenvolvido. Além disso, o fato de o uso do material didático do PLE ser efetivo foi um critério importante de escolha. O entorno da escola apresenta uma área urbanizada e há diversos estabelecimentos comerciais nas proximidades. A maioria dos alunos reside com os pais, que demonstram boa participação na vida escolar dos filhos, estando presente nas festividades escolares, na Associação de Pais e Mestres (APM) e nas reuniões de pais e mestres. O nível de escolaridade predominante entre esses responsáveis é o ensino médio completo. Segundo informações da escola, 50\% das famílias possuem computador em casa com internet e mais de um trabalhador efetivo.

A sala de aula observada apresentava um alfabeto acima da lousa, um cartaz com os nomes dos alunos, um espaço para fixar produções realizadas, desenhos relacionados às histórias lidas pela professora e aos projetos trabalhados, cartazes com o gráfico das idades dos alunos e com a tabuada. Na sala de aula, encontramos ainda uma cesta com paradidáticos, gibis e 
revistas infantis; caixa com brinquedos, bonecas, carrinhos, panelinhas, corda, entre outros. Próximo à caixa com brinquedos, havia um tapete. A sala também contava com armários e prateleiras para armazenar materiais, tais como: letras móveis, globo terrestre e potes com tampas de garrafa pet.

Salientamos que a entrevista com a professora foi realizada para melhor compreensão sobre o trabalho pedagógico realizado por ela. Destacamos que a professora pesquisada possui formação superior em pedagogia e leciona há dez anos no ensino fundamental, sendo o segundo ano em que trabalha nessa escola. Em seu percurso profissional, trabalhou a maior parte do tempo com $4^{\circ}$ e $5^{\circ}$ anos do EF e no ano anterior trabalhou com uma sala de $3^{\circ}$ ano do EF. Ela considerou que no início foi difícil trabalhar com o $1^{\circ}$ ano do EF e que foi preciso um período de adaptação, principalmente para os alunos se ambientarem à dinâmica desse nível de ensino.

\section{Resultados e análises: contextos da professora e dos alunos - as propostas mais valorizadas e os desafios encontrados}

O material do PLE chegou à escola investigada por volta do mês de abril, quando a professora começou a trabalhar segundo a perspectiva orientada pelo material, propondo atividades que constavam tanto na Coletânea de Atividades como no Livro de Textos do aluno. No período em que a pesquisa de campo foi realizada, o Projeto Índios do Brasil estava sendo trabalhado em sala de aula.

Em relação às propostas de leitura de texto, destacamos duas atividades da Coletânea de Atividades que continham imagens de povos indígenas com legendas as quais a professora solicitava aos alunos que lessem. Os textos exploravam as características e os hábitos dos povos indígenas e a professora se encarregava de destacar os principais aspectos do conteúdo e comentar com os alunos. Nesses momentos, também solicitava a participação oral destes, socializando impressões. Dessa forma, apesar de muitas informações serem trocadas e, durante as entrevistas, os alunos comentarem sobre elas, esses momentos de leitura foram qualificados pela grande maioria como "cansativos" e "chatos". Foi possível observar em sala de aula que essas leituras, além de serem longas, aconteciam com pouca interação entre professora e alunos e sempre da mesma forma - a professora à frente da classe, realizando questionamentos pontuais sobre as informações dos textos.

Destacamos que, principalmente nas atividades com imagens legendadas, a professora selecionava alunos para ler à frente na sala. Consideramos que as legendas representam um gênero de escrita com informações precisas, em um texto curto, que pode facilitar a leitura dos alunos e por essa razão torná-la mais atrativa para eles. Segundo o documento Pró-Letramento: Programa de Formação Continuada de Professores dos Anos/Séries Iniciais do Ensino Fundamental - Alfabetização e Linguagem (Brasil. MEC, 2008), o ato de ler contempla capacidades 
relativas à decifração do código escrito, como também capacidades em relação à compreensão e à produção de sentido. Dessa forma, a legenda, ao associar imagem e escrita, contribui fortemente tanto para a compreensão como para a produção de sentidos.

Segundo Colomer e Camps (2002), ler significa mais do que simplesmente um ato mecânico de decifração. Significa um ato de raciocínio, no sentido de construir a interpretação da mensagem escrita, a partir tanto da informação proporcionada como dos conhecimentos do leitor. As autoras enfatizam a importância de serem trabalhados em sala de aula os usos e as funções sociais dos textos escritos. Tal ideia relaciona-se com a proposta defendida por Soares (2012) de alfabetizar letrando.

Os dados apontaram, no entanto, que, embora as legendas possam trazer facilidades de leitura e interpretação para os alunos que estão se alfabetizando, é um desafio produzi-las. As atividades de elaboração de legenda foram propostas pela professora de diferentes maneiras. Dessa forma, na Coletânea de Atividades (São Paulo, 2011b), havia propostas que abordavam a construção de legendas para imagens de povos indígenas em situações costumeiras de suas vivências. Salientamos que a professora conduziu as propostas de maneiras diferentes, porém, em todos esses momentos, observamos que a professora promoveu a exploração em sala do contexto das imagens, de modo que os alunos podiam participar de forma oral, livremente, expondo suas opiniões. Entretanto, a escrita final da legenda na lousa não estabelecia uma relação mais direta com o que os alunos falavam, nem mesmo como contraponto para promover reflexões a respeito da coerência do conteúdo expresso pelos alunos.

Ponderamos a complexidade da elaboração das legendas, pois a escrita desse gênero exige grande capacidade de síntese. Consideramos, nesse sentido, que a professora percebia a dificuldade dos alunos ao escrever as legendas e, por isso, acabava conduzindo a elaboração do texto. Mesmo ouvindo as proposições orais dos alunos, optava por reproduzir na lousa exemplos de legendas que o Guia sugeria.

Outro momento foi a leitura de um texto do Livro de Textos do aluno. Tal leitura foi realizada pela professora e estava prevista para acontecer todos os dias na rotina da sala. Antes de iniciar, a professora comentou as características do gênero do texto e forneceu informações sobre o seu conteúdo. A professora lia e os alunos ouviam em suas carteiras, sem o compromisso de acompanhar a leitura no material. Sua orientação era para que apenas ouvissem. Foi observado que, embora os alunos parecessem atentos, no momento de realizarem o desenho ilustrando parte do conteúdo lido, alguns apresentaram produções descontextualizadas da leitura realizada.

Foi ainda observada a realização de uma atividade com a música Pindorama. Os alunos ouviram a música para aprender, depois acompanharam no material e cantaram. Nesse momento, mesmo que a professora não tenha explorado o conteúdo da cantiga, essa atividade foi a preferida na opinião dos alunos pelo fato de terem cantado. Entretanto, observamos em sala de aula, com a confirmação das entrevistas, que 
os alunos sentiram dificuldades para acompanhar a música no material, assim como para desenhar sobre o conteúdo de suas estrofes. No Guia de Planejamento e Orientações Didáticas (São Paulo, 2011a), há orientações anteriores a respeito da introdução da música no contexto do Projeto Índios do Brasil, pois aborda o descobrimento do Brasil. Nesse sentido, no material, sugere-se a leitura de um texto sobre esse fato histórico a fim de preparar a discussão com a sala.

Os textos a serem trabalhados nessa faixa etária devem explorar em seu conteúdo elementos que possam ser discutidos, refletidos e compreendidos, promovendo, assim, avanços na aprendizagem da criança. Além disso, é preciso que façam sentido para que a criança possa alcançar uma compreensão lógica sobre a proposta. Cabe salientar que, na perspectiva do letramento, a iniciativa é a de trabalhar textos verdadeiros, ${ }^{3}$ que possibilitam que o aluno articule o apreendido na sala de aula com sua vivência na sociedade.

Pensando na relação discursiva, segundo Marcuschi (2003), assumir o texto como recurso discursivo significa compreender que esse texto (e/ou produção textual) se estabelece em uma situação de interação por meio da linguagem em contextos significativos. O texto, nessas condições, concretiza-se como uma ação de ordem comunicativa, com estratégias convencionais, tendo a finalidade de atingir determinados objetivos. O texto se faz nessa perspectiva como uma manifestação concreta do discurso. De acordo com essa concepção, temos que compreender o texto como uma produção concreta de comunicação entre interlocutores e, da mesma forma, assumi-lo como uma unidade de sentido em que o uso real da escrita se concretiza pela interlocução.

Ainda durante o trabalho com o Projeto Índios do Brasil, além das propostas do material, houve a realização de atividades em lousa, como elaboração de uma lista de ervas medicinais utilizadas pelos indígenas, caçapalavras sobre alimentos típicos, escrita de elementos do contexto indígena contidos em um desenho, escrita de legendas e leitura de lendas indígenas. A professora comentou que essas atividades estão de acordo com a proposta do Ler e Escrever, pois contemplam localização de palavras, realização de listas, escrita de legendas e leitura. Os alunos realizaram também, como tarefa de casa, pesquisas sobre os povos indígenas. Eram selecionados alguns cadernos para mostrar as imagens escolhidas pelos alunos, assim como as informações trazidas. Em outro momento, os alunos assistiram a um vídeo sobre o contexto atual dos índios no Brasil. Houve ainda plantio de sementes em garrafas pet, atividades culinárias, como bolo de tapioca e de mandioca, e passeio em um sítio com realização de palestra proferida por um cacique. Salientamos que esses momentos foram comentados pela professora em sua entrevista, porém, em sala de aula, nos momentos de observação, ela brevemente os mencionava, e os alunos, por sua vez, não comentaram sobre tais atividades. Somente dois alunos, nas entrevistas, mencionaram essas experiências e relacionaram as informações obtidas como importantes para o aprendizado a respeito dos hábitos e costumes indígenas. Destacaram, por exemplo, situações cotidianas dos índios, como 
o preparo de alimentos, tendo sido marcante para os alunos a informação de que as crianças indígenas também frequentavam escolas.

Segundo Batista (2009, p. 72), a interação, a ação sobre objetos variados, é imprescindível para o desenvolvimento intelectual da criança nessa faixa etária. A autora também considera que as atividades propostas podem ser organizadas de forma a propiciar contato real com o objeto de estudo e trocas entre os pares e com a professora que promovam um avanço nas funções do pensamento. Desse modo, podemos dizer que há maiores chances de progresso na aprendizagem e no desenvolvimento dos alunos. Como salienta a autora, as atividades diversificadas no $1^{\circ}$ ano do EF são importantes porque "elas constituem um meio de propiciar a interação social e a cooperação, como também provocam conflitos, fazendo a criança refletir sobre sua hipótese". Destacamos que as atividades complementares contribuíram para que, especialmente o Projeto Indios do Brasil, fosse vivenciado e concretizado de outras formas que propiciaram aspectos que a autora sublinhou, como cooperação, interação, vivência real e reflexão sobre hipóteses.

Consideramos que o trabalho pedagógico com base no Projeto Índios do Brasil, apesar de certas dificuldades apontadas, principalmente por meio das entrevistas, proporcionou o avanço de novos conhecimentos, tanto para a professora como para os alunos. Por meio das vivências relacionadas às propostas da Coletânea de Atividades e às atividades extracurriculares sobre o contexto dos índios, podemos construir e aperfeiçoar conhecimentos e informações.

Nessa perspectiva, a partir das observações das propostas, foi possível também destacar dois eixos de compreensão: um centrado no comportamento dos alunos perante o material pesquisado e outro em função da prática pedagógica da professora.

\section{Os alunos do $1^{\circ}$ ano e o Ler e Escrever}

Durante as observações em sala de aula, registramos tanto manifestações de satisfação quanto de desagrado quando a professora anunciava que iriam trabalhar com o material didático do Programa Ler e Escrever. Mesmo diante de posições antagônicas, de maneira geral, os alunos participavam dando opiniões e respondendo às questões da professora durante o trabalho.

Ressaltamos que a participação mais efetiva dos alunos ocorria geralmente durante a leitura das legendas. Embora eles não tenham demonstrado compreensão plena da forma de elaborá-las, a leitura das legendas do material foi algo importante em virtude do interesse dos alunos em lê-las.

Algo que merece ser ressaltado é que, nos momentos de leitura em que a professora utilizou o Livro de Textos do aluno, houve maior envolvimento e atenção da classe. Acreditamos que os alunos se relacionaram de modos distintos com as temáticas de cada um dos materiais, haja vista que no 
Livro de Textos a professora selecionava geralmente assuntos do cotidiano e da vivência dos alunos.

As questões mencionadas acima sobre a leitura estão, de certa forma, relacionadas com a adaptação da criança de seis anos no $1^{\circ}$ ano do EF. Como sinaliza Rapoport et al. (2009), esse momento é marcado muitas vezes por insegurança, ansiedade ou medo, o que vai ao encontro dos apontamentos dos alunos pesquisados. Temos que a estrutura e os conteúdos do $1^{\circ}$ ano devem considerar o perfil de seus alunos, portanto, atividades desarticuladas com a faixa etária podem trazer algumas insatisfações.

Mais uma vez em referência ao material didático do PLE, observamos que era uma prática frequente por parte dos alunos folhear o material pesquisado, fazer comentários e ler as atividades anteriores. As principais atividades comentadas por eles foram, geralmente, as que continham cantigas e parlendas, as que envolviam brincadeiras e as que exploravam os nomes dos colegas. Assim, durante as entrevistas, os comentários dos alunos, na maioria das vezes, estavam relacionados às atividades que compõem a cultura infantil.

Ratificamos a importância de as propostas estarem engajadas tanto ao contexto dos alunos quanto a uma concepção de leitura e escrita reais que se transporte para a compreensão sobre o sentido e a função social da linguagem escrita, contribuindo para a reflexão sobre a língua.

Destacamos que, em relação ao Projeto Índios do Brasil, os principais apontamentos foram referentes às imagens dos índios. Os alunos, muitas vezes, explicavam o que aprenderam sobre os costumes e a cultura indígena, de modo que inferimos que a aprendizagem de conhecimentos relacionados a contextos e culturas diferentes atraiu os alunos.

Corsino (2006) aponta a importância de propor formas para que a criança nessa faixa etária tenha condições de ampliar seu universo cultural, refletir de forma crítica sobre as relações humanas e os problemas enfrentados. A autora aponta que é importante a criança ampliar a reflexão sobre sua própria história, suas formas de viver e também de se relacionar. Desse modo, a socialização de vivências entre os alunos e a identificação de semelhanças e diferenças entre os grupos sociais, sejam estes próximos ou conhecidos por meio de histórias, são importantes para o desenvolvimento de atitudes de reflexão e observação do mundo ao seu redor e de suas transformações.

Baseando-nos em Corsino (2006), consideramos que o estudo sobre os povos indígenas foi importante, nessa faixa etária, para o conhecimento sobre as diferentes formas de ação humana, de povoamento e de urbanização existentes no mundo. Além disso, a autora destaca que, por meio de temáticas como essa, a criança tem condições de se reconhecer na realidade em que vive e se reconhecer também como parte da natureza e da cultura.

No que diz respeito ao manuseio e funcionamento do material, observamos dificuldade em relação à quantidade e ao número das páginas. 
Sobre isso, alguns alunos comentaram: "tem um monte de páginas". Para encontrar a página de uma atividade anunciada, muitos folheavam uma a uma. Da mesma forma, foi observado que havia aqueles que se orientavam pela última atividade realizada e não necessariamente pelo número da página.

Tanto nas entrevistas como durante as observações em sala de aula, os alunos gostavam de comentar sobre as palavras cuja escrita já conheciam. Destacaram palavras que já sabiam escrever, como o nome das brincadeiras e também dos animais que compunham uma cruzadinha. Como exemplo, ressaltamos que, no momento em que estavam realizando uma lista de alimentos típicos dos indígenas, uma aluna disse: "Eu já sei escrever milho!".

Era comum também averiguarem entre si como cada um se saía na leitura e na escrita. Observamos que havia entre os alunos anseio por adquirir fluência em ambos os processos. Nos momentos de leitura, foram frequentes os comentários entre os alunos sobre quem sabia e quem não sabia ler. Além disso, muitos alunos se esforçavam na leitura compartilhada em sala e prestavam atenção na condução dessa proposta. Da mesma forma, esses momentos estiveram em evidência durante as entrevistas, pois muitos alunos pediam: "Posso ler para você?!". Salientamos que os alunos, nas entrevistas, leram também, na maioria das vezes, as legendas das imagens dos índios.

\section{O trabalho pedagógico da professora}

Em se tratando dos procedimentos da professora, especificamente nas atividades do material pesquisado, há comportamentos recorrentes, como o de escrever o número da página na lousa e explorar a formação do número, mesmo que brevemente. Ela orientava também a escrita do nome completo dos alunos e da data nos lugares indicados no material. Embora a data já estivesse discriminada no cabeçalho por extenso (por exemplo: Campinas, 19 de setembro de 2012), a professora colocava na lousa, todas as vezes, a data no formato indicado no material (19/09/2012).

Outra prática costumeira era a realização de uma revisão das atividades anteriores antes de iniciar uma nova atividade. Destacamos, nesse sentido, que a professora privilegiava a participação oral dos alunos, e, assim, coletivamente, o grupo relembrava informações pontuais e conceitos trabalhados. Era muito comum também a professora repetir orientações e/ou instruções dadas aos alunos e enfatizá-las, consecutivamente, para que os alunos prestassem atenção na explicação da proposta, bem como na sua realização. Em relação à postura da professora na condução das propostas, geralmente estava à frente da sala e, raramente, passava entre as carteiras para observar as atividades que os alunos estavam realizando.

A respeito do conteúdo do material do Ler e Escrever, a professora considerou importante o trabalho com os nomes dos alunos e com listas, cantigas e parlendas, que julgou serem de fácil memorização. Em relação ao 
Projeto Índios do Brasil, destacou a frequência de propostas com imagens de indígenas para a elaboração de legendas. A professora ainda considerou as propostas do material insuficientes para alfabetizar os alunos, pois julgou necessário buscar alternativas para complementar o trabalho pedagógico.

Na impressão da professora, o material também poderia contemplar mais propostas que estivessem ligadas a temáticas próprias da cultura infantil e que fizessem sentido para os alunos. O Projeto Brincadeiras Tradicionais, em sua opinião, deveria ser ampliado porque "foi algo que eles gostaram". Em relação ao Projeto Índios do Brasil, segundo ela, a quantidade de propostas com textos tornou "mais difícil" a compreensão do trabalho para os alunos.

Ponderamos que as especificidades dos projetos trabalhados na Coletânea de Atividades do $1^{\circ}$ ano possibilitaram que os alunos se relacionassem de maneiras diferentes com as atividades de cada um deles. O Projeto Brincadeiras Tradicionais, por si só, apresentava uma temática que estava mais próxima das vivências dos alunos e trouxe a possibilidade de socialização de brincadeiras que não faziam mais parte do cotidiano das crianças de hoje. Já o Projeto Índios do Brasil - Conhecendo algumas Etnias proporcionou tanto para a professora quanto para os alunos o conhecimento de novos elementos culturais, que foram destacados por ambos.

\section{Considerações finais}

Diante dos dados apresentados, consideramos que a leitura e a escrita fazem parte do momento que a criança do $1^{\circ}$ ano está vivenciando e, por isso, geram curiosidades e desejo de aprender, pois tal aprendizagem possibilita a inserção na sociedade letrada. Mesmo que indiretamente, a criança reconhece o valor de saber ler e escrever.

Podemos dizer, com base nos dados empíricos, que sobressaiu com frequência nas entrevistas com os alunos o gosto por saber ler e escrever. Igualmente, os alunos relacionaram a leitura e a escrita à aprendizagem e ao conhecimento. É desejo das crianças nessa faixa etária saberem ler e escrever, porque compreendem que isso lhes confere maior autonomia e acesso a informações que avaliam como necessárias.

Ressaltamos que a centralidade da escrita nos modos de organização e funcionamento da sociedade faz com que a criança, mesmo antes de seu ingresso na escola, esteja em contato com algumas formas de uso da escrita. Tal contexto confere à criança descobertas aliadas ao anseio de compreender, progressivamente, seu funcionamento e sua finalidade. Dessa forma, consideramos que esse aprendizado se constitui como um momento rico do desenvolvimento da criança, pois promove um salto qualitativo em suas formas de pensar e agir, bem como em suas relações com o mundo. Consideramos que a qualidade dessas apropriações dependerá do acesso da criança à leitura e à escrita e de como isso lhe será proporcionado. Portanto, depende grandemente da mediação. 
De acordo com as possibilidades que são oferecidas aos alunos, compreendemos que terão maiores oportunidades de inferir sobre o mundo e dele apreender novas possibilidades. Os caminhos são múltiplos. O apoio do material didático pode contribuir, nesse sentido, satisfatoriamente, para a aquisição da linguagem escrita. Entretanto, a mediação e o uso que se faz desse material são fundamentais. Ressaltamos a atuação do professor, em especial a forma como ele planeja o ensino e promove a aprendizagem em sala de aula.

Destacamos a importância da apropriação tanto das propostas de programas educacionais nos moldes do PLE como das concepções teórico-metodológicas subjacentes a esses programas. Acreditamos que tal apropriação pertence de fato à formação do professor, entretanto, ponderamos que o trabalho coletivo da equipe escolar faz diferença, pois, discutindo com o grupo, o professor tem maiores condições de refletir sobre os desafios de sua sala de aula.

\section{Referências bibliográficas}

BATISTA, Cleide Vitor Mussini. A educação da criança de seis anos. In: BRANDÃO, Carlos da Fonseca; PASCHOAL, Jaqueline Delgado. Ensino fundamental de nove anos: teoria e prática na sala de aula. São Paulo: Avercamp, 2009. cap. 4.

BRASIL. Lei $\mathrm{n}^{\circ} 11.274$, de 6 de fevereiro de 2006. Altera a redação dos arts. 29, 30, 32 e 87 da Lei no 9.394, de 20 de dezembro de 1996, que estabelece as diretrizes e bases da educação nacional, dispondo sobre a duração de 9 (nove) anos para o ensino fundamental, com matrícula obrigatória a partir dos 6 (seis) anos de idade. Diário Oficial da União, Brasília, DF, 7 fev. 2006. Disponível em: <https://www.planalto.gov.br/ ccivil_03/_Ato2004-2006/2006/Lei/L11274.htm>.

BRASIL. Lei n ${ }^{\circ}$ 6.094, de 24 de abril de 2007. Dispõe sobre a implementação do Plano de Metas Compromisso Todos pela Educação, pela União Federal, em regime de colaboração com Municípios, Distrito Federal e Estados, e a participação das famílias e da comunidade, mediante programas e ações de assistência técnica e financeira, visando a mobilização social pela melhoria da qualidade da educação básica. Diário Oficial da União, Brasília, DF, 25 abr. 2007. Disponível em: <http://www.planalto.gov.br/ccivil_03/_ato2007-2010/2007/decreto/ d6094.htm>. 
BRASIL. Ministério da Educação (MEC). Secretaria de Educação Básica (SEB). Ensino fundamental de nove anos: orientações gerais. Brasília, DF, 2004. Disponível em: <http://portal.mec.gov.br/seb/arquivos/pdf/ Ensfund/noveanorienger.pdf $>$.

BRASIL. Ministério da Educação (MEC). Secretaria de Educação Básica (SEB). Capacidades linguísticas: alfabetização e letramento. In: BRASIL. Ministério da Educação (MEC). Secretaria de Educação Básica (SEB). Pró-Letramento: Programa de Formação Continuada de Professores dos Anos/Séries Iniciais do Ensino Fundamental: alfabetização e linguagem. Ed. rev. e ampl. Brasília, DF, 2008. p. 6-56.

COLOMER, Teresa; CAMPS, Anna. Ensinar a ler, ensinar a compreender. Porto Alegre: Artmed, 2002.

CORSINO, Patrícia. As crianças de seis anos e as áreas do conhecimento. In: BRASIL. Ministério da Educação (MEC). Secretaria de Educação Básica (SEB). Ensino fundamental de nove anos: orientações para a inclusão da criança de seis anos de idade. Brasília: FNDE, Estação Gráfica, 2006.

CRUZ, Silvia Helena Vieira (Org.). A criança fala: a escuta de crianças em pesquisa. São Paulo: Cortez, 2008.

LEITE, Sérgio Antônio da Silva. Notas sobre alfabetização escolar. In: LEITE, Sérgio Antônio da Silva (Org.). Alfabetização e letramento: contribuições para as práticas pedagógicas. 4. ed. Campinas, SP: Komedi, 2008.

MARCUSCHI, Luiz Antônio. Gêneros textuais: definição e funcionalidade. In: DIONISIO, Ângela Paiva; MACHADO, Anna Rachel; BEZERRA, Maria Auxiliadora (Org.). Gêneros textuais e ensino. Rio de Janeiro: Lucena, 2003. p. 20-36.

PÁDUA, Elisabete Matallo Marchesini de. Metodologia da pesquisa: abordagem teórico-prática. 6. ed. Campinas, SP: Papirus, 2000.

PASSEGGI, M. da C.; FURLANETTO, E. C.; CHAVES, I. M.; CONTI, L. de; CAMPELO, M. E. C. H.; GOMES, M. de O.; ROCHA, S. M. O que contam as crianças sobre as escolas da infância. In: ENCONTRO NACIONAL DE DIDÁTICA E PRÁTICAS DE ENSINO, 16., 2012, Campinas. Anais eletrônicos... Araraquara: Junqueira \& Marin, 2012. Cd-rom.

RAPOPORT, Andrea; SARMENTO, Dirléia Fanfa; NÖRNBERG, Marta; PACHECO, Suzana Moreira (Org.). A criança de 6 anos no ensino fundamental. Porto Alegre: Mediação, 2009. 
ROCHA, Eloisa Acires Candal. A pesquisa em educação infantil no Brasil: trajetória recente e perspectivas de consolidação de uma pedagogia. Florianópolis: Núcleo de Publicações (NUP)/ UFSC, 1999. 290 p.

SÃO PAULO. Secretaria Estadual de Educação (SEE). Comunicado da SE, de 19 de dezembro de 2007. Diário Oficial do Estado, São Paulo, 21 dez. 2007, 2007a.

SÃO PAULO. Secretaria Estadual de Educação (SEE). Resolução $S E n^{\circ}$ 22, de 29 de março de 2007. Dispõe sobre Grupo de Trabalho para implantação e desenvolvimento dos Programas Ler e Escrever e Bolsa Formação - Escola Pública e Universidade. São Paulo, 2007b. Disponível em: <http://siau.edunet.sp.gov.br/ItemLise/arquivos/22_07.HTM >.

SÃO PAULO. Secretaria Estadual de Educação (SEE). Resolução SE $n^{\circ}$ 86, de 19 de dezembro de 2007. Institui, para o ano de 2008, o Programa "Ler e Escrever", no Ciclo I das Escolas Estaduais de Ensino Fundamental das Diretorias de Ensino da Coordenadoria de Ensino da Região Metropolitana da Grande São Paulo, 2007c. Disponível em: <http://siau.edunet.sp.gov.br/ItemLise/arquivos/86_07. HTM?Time=04/03/2015\%2014:59:38>.

SÃO PAULO. Secretaria Estadual de Educação (SEE). Resolução $S E n^{\circ}$ 96, de 23 de dezembro de 2008. Estende o Programa "Ler e Escrever" para as Escolas Estaduais de Ensino Fundamental do Interior. São Paulo, 2008. Disponível em: <http://siau.edunet.sp.gov.br/ItemLise/ arquivos/96_08.HTM?Time=04/03/2015\%2015:02:48>.

SÃO PAULO. Secretaria Estadual de Educação (SEE). Fundação para o Desenvolvimento da Educação. Ler e escrever: guia de planejamento e orientações didáticas: professor alfabetizador: $1^{\circ}$ ano. 2. ed. São Paulo: FDE, 2011a.

SÃO PAULO. Secretaria Estadual de Educação (SEE). Fundação para o Desenvolvimento da Educação. Ler e escrever: coletânea de atividades: $1^{\circ}$ ano. 2. ed. São Paulo: FDE, 2011b.

SÃO PAULO. Secretaria Estadual de Educação (SEE). Fundação para o Desenvolvimento da Educação. Programa ler e escrever. 2010. Disponível em: <http://lereescrever.fde.sp.gov.br/SysPublic/Home.aspx>. Acesso: abr. 2012.

SOARES, Magda. Letramento: um tema em três gêneros. 3. ed. Belo Horizonte: Autêntica, 2012. 
Tatiana Cristina Santos é mestre em Educação pela Pontifícia Universidade Católica de Campinas (PUC-Campinas) e, atualmente, é integrante do grupo de pesquisa Formação e Trabalho Docente da Linha de Pesquisa Formação de Professores e Práticas Pedagógicas, na PUCCampinas, São Paulo, Brasil.

tatics23@hotmail.com

Elvira Cristina Martins Tassoni, doutora em Educação pela Universidade Estadual de Campinas, é docente do Programa de Pós-Graduação em Educação da Pontifícia Universidade Católica de Campinas (PUC-Campinas), São Paulo, Brasil.

cristinatassoni@gmail.com

Recebido em 10 de fevereiro de 2014.

Solicitação de correções em 20 de novembro de 2014.

Aprovado em 4 de dezembro de 2014. 